\section{Opening propofol ampoules safely}

To the Editor:

I'd like to draw the readers attention on the letter published by Huda and Kahn in the 2001 July/August issue of the Canadian Journal of Anesthesia regarding their technique of opening ampoules. ${ }^{1}$

An identical technique with an almost identical figure has been published by us in 1997, in another journal. ${ }^{2}$

Yitzhak Cohen MD

Lucio Glantz MD

Tiberiu Ezri MD

Holon, Israel

\section{References}

l Huda W, Khan RM. Opening an ampoule? Start from scratch. Can J Anesth 2001; 48: 715.

2 Cohen $\Upsilon$, Glantz L, Ezri T. Breaking glass vials. Anesthesiology 1997; 86: 1215.

\section{REPLY:}

We thank you for giving us the opportunity to respond to the comments made by Cohen, Glantz and Ezri on our article entitled "Opening an ampoule? Start from a scratch", published in the 2001 July/August issue of the Canadian Journal of Anaesthesia. ${ }^{1}$

We agree that the technique of breaking the non snapoff ampoules, which is commonly practiced at our centre and was independently reported by us, is the same as that of Cohen, Glantz and Ezri. However we modified this method to break propofol ampoules specifically.

These partially, one point cut ampoules, when broken as instructed by the manufacturer often result in the formation of a sharpened vertical spike, which may lead to injury, even to the extent of requiring plastic surgery. ${ }^{2-4}$ The fact that various techniques were proposed to break these one point cut propofol ampoules without the formation of spikes, ${ }^{4-6}$ prompted us to apply the method in question - rubbing the bottom edge of an ampoule against the neck of another - to break these ampoules specifically.

Thus, though the two techniques are similar, we have emphasized the use of this technique for breaking open propofol ampoules in a spikeless fashion.

Wasimul Huda MBBS MD

Rashid M. Khan MD

Aligarh, India

\section{References}

1 Huda W, Khan RM. Opening an ampoule? Start from a scratch. Can J Anesth 2001; 48: 715.
2 Ali PB. Persistent problem with propofol ampoules. Anaesthesia 1997; 52: 1020.

3 Palmer J, Ball D. Opening propofol ampoules. Anaesthesia 1998; 53: 416-7.

4 Morrison WJ. Another cracking idea. Anaesthesia 1999; 54: 307-8.

5 Smith $I$. The direct flick method for opening ampoules. Anaesthesia 1998; 53: 830.

6 Koga K, Hirose M. Scissors as a propofol ampoule 'snapper'? Anaesthesia 1999; 54: 919-10. 